\title{
Sutureless aortic valve replacement in multivalve procedures
}

\author{
Alina Zubarevich ${ }^{1}$, Marcin Szczechowicz ${ }^{1}$, Konstantin Zhigalov ${ }^{1}$, Anja Osswald ${ }^{1}$, Jef Van den Eynde ${ }^{2}$, \\ Arian Arjomandi Rad ${ }^{3}$, Robert Vardanyan ${ }^{3}$, Daniel Wendt ${ }^{1}$, Bastian Schmack ${ }^{1}$, Arjang Ruhparwar ${ }^{1}$, \\ Alexander Weymann ${ }^{1}$ \\ ${ }^{1}$ Department of Thoracic and Cardiovascular Surgery, West German Heart and Vascular Center, University of Duisburg-Essen, Essen, Germany; \\ ${ }^{2}$ Department of Cardiovascular Diseases, University Hospitals Leuven, Leuven, Belgium; ${ }^{3}$ Department of Medicine, Faculty of Medicine, Imperial \\ College London, London, UK \\ Contributions: (I) Conception and design: A Zubarevich; (II) Administrative support: B Schmack, A Ruhparwar, D Wendt, A Weymann; (III) Provision \\ of study materials or patients: A Zubarevich; (IV) Collection and assembly of data: A Zubarevich, M Szczechowicz, K Zhigalov, A Osswald, J Van den \\ Eynde, A Arjomandi Rad, R Vardanyan; (V) Data analysis and interpretation: All authors; (VI) Manuscript writing: All authors; (VII) Final approval \\ of manuscript: All authors. \\ Correspondence to: Alina Zubarevich, MD. Department of Thoracic and Cardiovascular Surgery, West-German Heart Center Essen, University \\ Hospital Essen, Hufelandstraße 55, 45122 Essen, German. Email: alina.zubarevich@gmail.com.
}

Background: Despite the rapid expansion of transcatheter approaches for aortic valve implantation,
surgical aortic valve replacement remains the treatment of choice in patients presenting with multiple
valvular heart disease. We sought to review our clinical experience with sutureless aortic valve replacement
(SU-AVR) in the setting of multivalve procedures, addressing the postoperative outcomes and technical
challenges.

Methods: Between December 2019 and December 2020, 20 consecutive high-risk patients at our institution underwent SU-AVR and concomitant mitral valve procedure for various indications.

Results: The mean age of the patients at operation was $72.6 \pm 9.3$ years. Fifty five percent of the patients $(n=11)$ presented with moderate to severe symptomatic aortic valve stenosis, while $35 \%(n=7)$ suffered from severe aortic regurgitation. All patients had concomitant moderate to severe mitral valve disease, including regurgitation in 95\% $(n=19)$ and stenosis in $25 \%(n=5)$. Mean logistic EuroSCORE was $34.3 \% \pm 24.7 \%$. Cardiopulmonary bypass and cross-clamp times were 101 (88.0-123) minutes and 67.5 (51.7-85.2) minutes, respectively. Optimal sutureless aortic valve prosthesis device success was achieved in 20 patients (100\%). One patient $(5 \%)$ required permanent pacemaker implantation. Thirty-day mortality was $10 \%$ and no strokes were detected.

Conclusions: SU-AVR is a safe and feasible surgical alternative to conventional procedures in patients presenting with multiple valvular heart disease. It provides excellent hemodynamic performance with low risk of paravalvular leakage and low transvalvular gradients, whilst simplifying the surgical procedure. Precise sizing and positioning of the valve prostheses is crucial to ensure optimal postoperative outcome.

Keywords: Sutureless aortic valve; Perceval; multivalve procedures; mitral valve procedure

Submitted Feb 02, 2021. Accepted for publication Apr 02, 2021.

doi: $10.21037 /$ jtd-21-300

View this article at: http://dx.doi.org/10.21037/jtd-21-300

\section{Introduction}

Despite the rapid expansion of transcatheter approaches for aortic valve implantation, the treatment of choice in patients presenting with multiple valvular heart disease remains surgical aortic valve replacement. Nonetheless, it is well known that cardiopulmonary bypass time and aortic cross-clamp time are important independent predictors of mortality in patients undergoing multivalve procedures (1). Approaches enabling a reduction in ischemia-reperfusion injury during valve procedures are very desirable, especially 
in the setting of complex valvular pathology and in patients with multiple comorbidities.

Sutureless aortic valve replacement (SU-AVR) has shown promising results in terms of excellent hemodynamic performance, ensuring low transvalvular gradients even in small aortic annuli. Furthermore, it leads to a drastic reduction in implantation time owing to its simplicity and reproducibility $(2,3)$. Nevertheless, the postoperative risk of paravalvular leakage (PVL) development results in SUAVR requiring decalcification of the aortic annulus (4). The Perceval S (LivaNova) sutureless aortic valve is a collapsible, stent-mounted, bovine-pericardium prosthesis with nitinol stent produced with nickel and titanium.

Although successful outcomes have been described after SU-AVR for extended indications, including infective endocarditis and bicuspid aortic valves (2), knowledge regarding the presence of a previously implanted mitral valve prosthesis or concomitant mitral valve surgery remains scarce. Indeed, SU-AVR in multivalve disease procedures is generally seen as problematic due to the possible interference of both prostheses at the level of the aorto-mitral continuity (5). Given this concern, SU-AVR is often excluded during when deciding the surgical approach of choice in patients presenting with multiple valvular pathologies.

To examine the validity of this concern, we sought to review our clinical experience with SU-AVR in the setting of multivalve procedures and address the postoperative outcomes and technical challenges.

We present the following article in accordance with the STROBE reporting checklist (available at http://dx.doi. org/10.21037/jtd-21-300).

\section{Methods}

\section{Study design and population}

Between December 2019 and December 2020, 20 consecutive high-risk patients underwent concomitant sutureless aortic valve replacement (SU-AVR) for various indications and mitral valve procedure at our institution, the West German Heart and Vascular Center Essen (Germany).

Preoperative evaluation of patients was performed by the interdisciplinary Heart Team at our institution, consisting of a cardiac surgeon, interventional cardiologist, and cardiac anesthesiologist. Postoperative echocardiographic evaluation of the implanted valve prosthesis function was performed before hospital discharge. Data was collected prospectively as a part of our institutional database, including detailed information on patients' demographics; baseline clinical characteristics; their laboratory, echocardiographic, and hemodynamic parameters; intraoperative variables; and postoperative outcomes. The study was conducted according to the Declaration of Helsinki (as revised in 2013). The ethical board of our institution approved the study protocol and data gathering and waived the need for individual informed consent (number of ethics approval 20-9738-BO). All patients signed the informed consent on follow-up.

\section{Surgical technique for SU-AVR and mitral valve procedures}

The chest was accessed via median sternotomy. Normothermic cardiac arrest was performed for all procedures. Cardiopulmonary bypass (CPB) was initiated with the direct cannulation of the ascending aorta and right atrium (with the exception of procedures involving tricuspid valve, here the bicaval cannulation was performed). Custodiol-HTK (Köhler Chemie GmbH, Bensheim, Germany) was administered via aortic route. A high transverse aortotomy was performed and the native aortic valve was decalcified and excised in toto.

For mitral valve procedures, the mitral valve was exposed through left atriotomy via Waterson's groove. For mitral valve repair, we used the Memo-4D ring (LivaNova) and for mitral valve replacement, Medtronic Hancock II (Medtronic) or Perimount (Edwards Lifesciences, Irvine, CA, USA) bioprostheses were used. In the case of mitral valve replacement, care should be taken with regards to the exact positioning of the struts of the valve bioprosthesis so as not to compromise the implantation of the aortic valve prosthesis through obstruction of the left ventricular outflow tract (LVOT). One of the struts is positioned halfway between the medial and lateral fibrous trigons of the mitral valve annulus, away from the aorto-mitral continuity not to compromise the LVOT.

Consequently, the Perceval S (LivaNova) sutureless aortic valve was implanted. It is crucial to size the sutureless prosthesis after the mitral valve procedure is completed. Indeed, the retractors used for the mitral valve procedure might lead to malpositioning of the sutureless aortic valve prosthesis. It should be noted that even the correct implantation of the prosthesis causes partial restriction of the LVOT. Therefore, the size of the sutureless prosthesis measured prior to the mitral valve implantation might not fit anymore. Following the decision on the size of the prosthesis, three 4.0 -prolene guiding sutures were placed 
in the middle point of each nadir, and the subsequent implantation was carried out in Snugger-technique, as previously described (6). The aortotomy was closed with 4.0-prolene double layered suture. After assessment of the prosthetic valves performance and careful de-airing using transesophageal echocardiography, the patient was separated from the CPB. The anticoagulation was reversed and after securing the hemostasis, the chest was closed with steel wires in routine fashion.

\section{Concomitant procedures}

In patients requiring coronary artery bypass surgery (CABG) left internal thoracic artery (LITA) was harvested using a pedicled or skeletonized technique, at the surgeon's discretion. As soon as cardioplegic arrest was initiated, target coronary vessels were identified and distal coronary anastomoses were performed in a regular fashion. If any proximal coronary anastomoses are required, they should be performed in cardiac arrest without additional clamping of the aorta to prevent damaging of the sutureless prosthesis.

Tricuspid valve annuloplasty was performed using Medtronic Duran AnCore Band on the beating heart in total cardiopulmonary bypass before administration of cardioplegic solution.

\section{Outcomes and definitions}

The primary end-points of this study were 30-day mortality and device success, evaluated via echocardiography. The secondary end-point was the development of any postoperative adverse events defined by the Valve Academic Research Consortium (VARC-2) (7). Patients presenting with logistic EuroSCORE $>20 \%$ were defined as high-risk patients.

\section{Statistical analysis}

The data were analyzed using IBM SPSS Version 27 (IBM Corporation, Chicago, IL, USA). We used the Shapiro-Wilk test to assess normality of the data. Quantitative data are expressed as the mean and standard deviation (SD) or median and interquartile range (IQR), according to distribution. Categorical data are expressed as frequency and percentage.

\section{Results}

\section{Baseline characteristics}

The mean age of the patients at operation was $72.6 \pm 9.3$ years (Table 1). Fifty five percent of the patients $(n=11)$ presented with severe symptomatic aortic valve stenosis, while $35 \%(n=7)$ suffered from severe aortic regurgitation. There were no bicuspid valves in the cohort and $26.6 \%$ of the patients $(n=4)$ suffered from isolated aortic regurgitation. All patients had concomitant moderate to severe mitral valve disease, including regurgitation in $95 \%$ $(\mathrm{n}=19)$ and stenosis in $25 \%(\mathrm{n}=5)$. Thirty five percent $(\mathrm{n}=7)$ of the patients were also diagnosed with moderate to severe tricuspid valve regurgitation. All patients suffered from multiple comorbidities, as presented in the Table 1 and reflected by a mean logistic EuroSCORE of $34.3 \% \pm 24.7 \%$.

\section{Intraoperative characteristics}

Intraoperative variables are listed in Table 2. All patients underwent SU-AVR using the Perceval S (LivaNova) sutureless aortic valve prosthesis and concomitant mitral valve procedure for various indications. Ten patients $(50 \%)$ underwent a concomitant mitral valve repair with an annuloplasty ring and in another 10 patients (50\%) a concomitant mitral valve replacement was performed. In addition, in 8 patients (40\%) a tricuspid valve repair with a Duran Band (Medtronic) was performed, and 4 patients (20\%) underwent a concomitant CABG procedure. Operating-and cross-clamp times were 189.5 (162.5-220.2) and $67.5(51.7-85.2)$ minutes, respectively.

\section{Postoperative outcomes}

Postoperative outcomes are listed in Table 3. In 20 patients $(100 \%)$, optimal device success of the sutureless aortic valve prosthesis was achieved. One patient died in tabula following atrioventricular rupture after decalcification of a severe calcified mitral valve, another patient died at postoperative day 2 because of acute right heart failure. We thus observed a 30 -day mortality of $10 \%$. Postoperative mean and peak gradients after SU-AVR implantation were $5.7 \pm 1.9$ and $11.7 \pm 2.3 \mathrm{mmHg}$, respectively. We observed no PVL and no postoperative mitral valve regurgitation. One patient suffered from postoperative third-degree atrioventricular block and underwent a permanent pacemaker implantation. We detected no postoperative stroke in our cohort.

\section{Discussion}

Concomitant significant mitral regurgitation (MR) left 
Table 1 Baseline characteristics

\begin{tabular}{|c|c|}
\hline Variables & $\%(n)$ \\
\hline Age, years & $72.6 \pm 9.3$ \\
\hline Female sex & $60 \%(n=12)$ \\
\hline BMI, $\mathrm{kg} / \mathrm{m}^{2}$ & $26.1 \pm 5.3$ \\
\hline Diabetes mellitus & $25 \%(n=5)$ \\
\hline Chronic obstructive pulmonary disease & $20 \%(n=4)$ \\
\hline Coronary artery disease & $40 \%(n=8)$ \\
\hline Prior PCl & $10 \%(n=2)$ \\
\hline Peripheral arterial disease & $15 \%(n=3)$ \\
\hline Prior stroke & $10 \%(n=2)$ \\
\hline Arterial hypertension & $100 \%(n=20)$ \\
\hline Pulmonary hypertension & $50 \%(n=10)$ \\
\hline Chronic kidney injury & $55 \%(n=11)$ \\
\hline Creatinine, mg/dL & $1.6 \pm 1.2$ \\
\hline GFR & $51.0 \pm 24.6$ \\
\hline Dialysis & $20 \%(n=4)$ \\
\hline \multicolumn{2}{|l|}{ NYHA Class } \\
\hline I-II & $30 \%(n=6)$ \\
\hline III-IV & $70 \%(n=14)$ \\
\hline LVEF, \% & $51.5 \pm 7.8$ \\
\hline Systolic PAP, mmHg & $44.5 \pm 16.5$ \\
\hline \multicolumn{2}{|l|}{ Rhythm } \\
\hline SR & $55 \%(n=11)$ \\
\hline AFib & $45 \%(n=9)$ \\
\hline Permanent pacemaker & $10 \%(n=2)$ \\
\hline logistic EuroSCORE, \% & $34.3 \pm 24.7$ \\
\hline \multicolumn{2}{|l|}{ Valvular pathologies } \\
\hline Moderare-to-severe MVR & $95 \%(n=19)$ \\
\hline Moderare-to-severe MVS & $25 \%(n=5)$ \\
\hline Moderare-to-severe TVR & $35 \%(n=7)$ \\
\hline Moderare-to-severe AVS & $55 \%(n=11)$ \\
\hline AV mean gradient & $29.1 \pm 20.4$ \\
\hline Aortic valve area & $1.3 \pm 0.4$ \\
\hline Aortic valve regurgitation & $60 \%(n=12)$ \\
\hline I-II & $25 \%(n=5)$ \\
\hline III & $35 \%(n=7)$ \\
\hline Infective endocarditis & $30 \%(n=6)$ \\
\hline
\end{tabular}

AFib, atrial fibrillation; BMI, body mass index; GFR, glomerular filtration rate; LVEF, left ventricular ejection fraction; NYHA, New York Heart Association Class; PAP, pulmonary arterial pressure; $\mathrm{PCl}$, percutaneous coronary intervention; SR, sinus rhythm.
Table 2 Intraoperative characteristics

\begin{tabular}{|c|c|}
\hline Variables & $\%(n)$ \\
\hline Emergency & $25 \%(n=5)$ \\
\hline Re-do & $20 \%(n=4)$ \\
\hline Operating-time, min & $189.5(162.5-220.2)$ \\
\hline Crossclamp-time, $\min$ & 67.5 (51.7-85.2) \\
\hline CPB-time, min & $100.5(88.0-123.75)$ \\
\hline \multicolumn{2}{|l|}{ Transfusions } \\
\hline Blood, Units & $3.0(0.5-4.0)$ \\
\hline Trombocytes, Units & $1.0(0.0-2.0)$ \\
\hline Fibrinogen, g & $2.0(0.0-4.0)$ \\
\hline \multicolumn{2}{|l|}{ SAVR (Perceval) } \\
\hline$S$ & $15 \%(n=3)$ \\
\hline M & $50 \%(n=10)$ \\
\hline $\mathrm{L}$ & $30 \%(n=6)$ \\
\hline$X L$ & $5 \%(n=1)$ \\
\hline Concomitant procedures & $100 \%(n=20)$ \\
\hline MV-repair & $50 \%(n=10)$ \\
\hline MV-replacement & $50 \%(n=10)$ \\
\hline TV-repair & $40 \%(n=8)$ \\
\hline CABG & $20 \%(n=4)$ \\
\hline MAZE-procedure & $5 \%(n=1)$ \\
\hline Myectomy & $10 \%(n=2)$ \\
\hline
\end{tabular}

CABG, coronary arterial bypass grafting; CPB, cardiopulmonary bypass; SAVR, surgical aortic valve replacement; MV, mitral valve; TV, tricuspid valve.

untreated at the time of AVR is an important and frequently encountered entity in the transcatheter aortic valve implantation (TAVI) era. Approximately $20 \%$ of patients undergoing TAVI present with moderate-to severe MR. The practice of not addressing this pathology has been associated with higher early and late mortality (8). There is still an ongoing debate about the impact of MR on elderly patients undergoing surgical isolated aortic AVR. Barreiro et al. (9) showed that moderate MR is an independent risk factor impacting long-term survival in elderly patients undergoing AVR. Therefore, there should be no hesitation in addressing this pathology in concomitant procedures. This single-center report presents favorable outcomes in patients undergoing SU-AVR and concomitant mitral valve 
Table 3 Postoperative characteristics

\begin{tabular}{lc}
\hline Variables & $\%(n)$ \\
\hline Exploration for bleeding & 0 \\
Acute kidney injury & $35 \%(\mathrm{n}=7)$ \\
Dialysis & $25 \%(\mathrm{n}=5)$ \\
Stroke & 0 \\
Cardiogenic shock & $5 \%(\mathrm{n}=1)$ \\
Extracorporeal Life Support & $5 \%(\mathrm{n}=1)$ \\
Paravalvular leackage & 0 \\
Residual MVR & 0 \\
AV mean gradient, mmHg & 5.71 .9 \\
AV peak gradient, mmHg & 11.72 .3 \\
Atril fibrillation & $35 \%(\mathrm{n}=7)$ \\
AVB III & $5 \%(\mathrm{n}=1)$ \\
Permanent pacemaker & $5 \%(\mathrm{n}=1)$ \\
Time on respirator, days & $1.0(1.0-2.0)$ \\
In-hospital stay, days & $7.5(3.5-12.75)$ \\
$30-$ day mortality & $10 \%(\mathrm{n}=2)$ \\
\hline AV, aortic valve; AVB, atrioventrictar & $\mathrm{MVR}, \mathrm{mit}$ (a) \\
\hline
\end{tabular}

$\mathrm{AV}$, aortic valve; $\mathrm{AVB}$, atrioventricular block; MVR, mitral valve regurgitation.

surgery.

New generation sutureless valve prostheses may provide an alternative therapeutic option for elderly and highrisk patients presenting with multiple valvular heart disease. Unfortunately, the presence of a prosthetic valve or annuloplasty ring in the mitral position presents a great technical challenge during SU-AVR. In our previous research we already suggested extending the indication for SU-AVR to patients presenting with more complex aortic valve pathologies (2). One of the central concerns in SUAVR in the setting of concomitant mitral valve procedures, remains the altering three-dimensional structure of the LVOT, and the direct interference of the mitral valve prosthesis with the sutureless aortic valve prosthesis $(5,10)$. Therefore, careful and exact positioning of the mitral valve prosthesis is crucial for the device success of the sutureless prosthesis. Minh et al. (5) suggested positioning the struts of the mitral valve prosthesis away from the aorto-mitral continuity, thus avoiding interference with the aortic valve prosthesis. In our cohort, optimal device success was achieved in $100 \%$ of the cases. Unfortunately, one patient suffered intraoperative left ventricular rupture and died in tabula. Left ventricular rupture is one of the most dreaded and often fatal complication in patients presenting with severe mitral valve stenosis undergoing mitral valve replacement (11). It is also of upmost importance to size the sutureless valve prosthesis once the mitral valve procedure is completed, as the mitral valve procedure itself tends to narrow the LVOT.

In our study one patient $(5 \%)$ required a permanent pacemaker due to third degree atrioventricular block. Previous studies on sutureless valve implantation show comparable rates of permanent pacemaker implantation in patients undergoing either isolated SU-AVR or SUAVR with concomitant mitral valve procedures $(2,10,12)$. Furthermore, lower rates of permanent pacemaker implantation in concomitant mitral valve surgery have been reported when SU-AVR was compared to conventional SAVR (13).

Concistrè et al. (14) described a large single-center cohort undergoing SU-AVR in combination with other procedures. They report $\mathrm{CPB}$ and aortic cross-clamp times $140 \pm 51.5$ and $91.5 \pm 29.5$ minutes, respectively. In our study, we observed CPB and aortic cross-clamp times of 101 (88.0-123) and 67.5 (51.7-85.2) minutes, respectively. The current literature confirms that prolonged CPB and crossclamp times remain significant determining factors for mediastinal blood loss, ICU and hospital length of stay, and in-hospital mortality (15).

The excellent hemodynamics of sutureless aortic valve prostheses has been previously described by us (2). In this high-risk cohort, despite concomitant mitral valve procedures we observed mean and peak transvalvular gradients of $5.7 \pm 1.9$ and $11.7 \pm 2.3 \mathrm{mmHg}$, respectively, being even lower than in the previously mentioned study by Concistrè et al. (14). The following can be explained by the extensive experience of the surgical team and appropriate attentiveness during the positioning of both the prostheses in order not to compromise the diameter of the LVOT, and to be able to implant the greatest size sutureless prosthesis possible to prevent postoperative high transvalvular gradients.

In our cohort we did not observe any cases of PVL after SU-AVR. Careful positioning of the prosthesis and proper decalcification of the aortic annulus might prevent postoperative PVL. Concistrè et al. (14) report $0.8 \%$ of moderate PVL at discharge, which we consider to be a very low rate, comparable to what observed in our study. The study group also suggests that oversizing of the 
Perceval prosthesis does not prevent PVL, carrying on the other hand a risk of incomplete expansion with possible invagination of the sutureless prosthesis. Baran et al. (10) reported supra-annular displacement of the sutureless prosthesis in $10 \%$ of the patients, which was associated with concomitant mitral valve replacement. PVL could be eliminated in almost all the cases with the redeployment of the valve prosthesis. In our cohort and in our previous experience we did not need to redeploy any sutureless prosthesis, so we suggest that precise positioning and sizing is even more important in multivalve procedures (2).

Disabling stroke is one of the most feared complications of cardiac procedures. In our cohort no patient suffered from any neurological complications, which correlates with the study of Baran et al. (10), who described a stroke rate of $3.3 \%$. Performing proximal CABG anastomoses on the cross-clamped aorta reduces extra manipulations and clamping of the ascending aorta, thus leading to reduced rates of cerebrovascular complications.

Previous studies describing concomitant SU-AVR procedure and mitral valve surgery reported similar 30 -day mortality to 1 our cohort $(5,10,14)$. In our study with multimorbid patients presenting with a mean logistic EuroSCORE $34.3 \pm 24.7$ we observed a 30 -day mortality of $10 \%$. One patient died in tabula because if the acute left ventricular rupture and another one suffered postoperative right ventricular failure, due to severe pulmonary hypertension.

\section{Conclusions}

SU-AVR is a safe and feasible surgical alternative to the conventional SAVR procedure in patients presenting with multiple valvular heart disease. During the operative approach decision making process, SU-AVR should be considered particularly for high-risk patients whose successful operative outcomes might be determined by a reduction in CBP and cross-clamp time. Moreover, patients undergoing complex procedures, where a longer cross-clamp time is expected, should also be taken into consideration for this procedure. SU-AVR provides superb hemodynamic performance with a low risk of PVL and low transvalvular gradients, whilst simplifying the surgical procedure. Extending the indications for SU-AVR towards multiple valvular procedures could significantly benefit the patients. Precise sizing and positioning of the valve prostheses is crucial for the postoperative outcome.

\section{Study limitations}

This study is limited by its retrospective, non-randomized singe-center nature and short follow-up time. Unfortunately, there are only few studies with small cohorts which examine this procedure. Further prospective studies on larger cohorts should be conducted to validate the safety and efficiency of this concept.

\section{Acknowledgments}

Funding: None.

\section{Footnote}

Reporting Checklist: The authors have completed the STROBE reporting checklist. Available at http://dx.doi. org/10.21037/jtd-21-300

Data Sharing Statement: Available at http://dx.doi. org/10.21037/jtd-21-300

Conflicts of Interest: All authors have completed the ICMJE uniform disclosure form (available at http://dx.doi. org/10.21037/jtd-21-300). Alexander Weymann is working as a proctor for LivaNova. The other authors have no conflicts of interest to declare.

Ethical Statement: The authors are accountable for all aspects of the work in ensuring that questions related to the accuracy or integrity of any part of the work are appropriately investigated and resolved. The study was conducted according to the Declaration of Helsinki (as revised in 2013). The ethical board of our institution approved the study protocol and data gathering and waived the need for individual informed consent (number of ethics approval 20-9738-BO). All patients signed the informed consent on follow-up.

Open Access Statement: This is an Open Access article distributed in accordance with the Creative Commons Attribution-NonCommercial-NoDerivs 4.0 International License (CC BY-NC-ND 4.0), which permits the noncommercial replication and distribution of the article with the strict proviso that no changes or edits are made and the original work is properly cited (including links to both the formal publication through the relevant DOI and the license). See: https://creativecommons.org/licenses/by-nc-nd/4.0/. 


\section{References}

1. Holst KA, Dearani JA, Burkhart HM, et al. Reoperative multivalve surgery in adult congenital heart disease. Ann Thorac Surg 2013;95:1383-9.

2. Mashhour A, Zhigalov K, Mkalaluh S, et al. Outcome of a Modified Perceval Implantation Technique. Thorac Cardiovasc Surg 2020;68:602-7.

3. Tasca G, Vismara R, Mangini A, et al. Comparison of the Performance of a Sutureless Bioprosthesis With Two Pericardial Stented Valves on Small Annuli: An In Vitro Study. Ann Thorac Surg 2017;103:139-44.

4. Gersak B, Fischlein T, Folliguet TA, et al. Sutureless, rapid deployment valves and stented bioprosthesis in aortic valve replacement: recommendations of an International Expert Consensus Panel. Eur J Cardiothorac Surg 2016;49:709-18.

5. Minh TH, Mazine A, Bouhout I, et al. Expanding the indication for sutureless aortic valve replacement to patients with mitral disease. J Thorac Cardiovasc Surg 2014;148:1354-9.

6. Mashhour A, Zhigalov K, Szczechowicz M, et al. Snugger method - The Oldenburg modification of perceval implantation technique. World J Cardiol 2018;10:119-22.

7. Kappetein AP, Head SJ, Généreux P, et al. Updated standardized endpoint definitions for transcatheter aortic valve implantation: the Valve Academic Research Consortium-2 consensus document. J Thorac Cardiovasc Surg 2013;145:6-23.

8. Nombela-Franco L, Ribeiro HB, Urena M, et al. Significant mitral regurgitation left untreated at the time

Cite this article as: Zubarevich A, Szczechowicz M, Zhigalov K, Osswald A, Van den Eynde J, Arjomandi Rad A, Vardanyan R, Wendt D, Schmack B, Ruhparwar A, Weymann A. Sutureless aortic valve replacement in multivalve procedures. J Thorac Dis 2021;13(6):3392-3398. doi: 10.21037/jtd-21-300 of aortic valve replacement: a comprehensive review of a frequent entity in the transcatheter aortic valve replacement era. J Am Coll Cardiol 2014;63:2643-58.

9. Barreiro CJ, Patel ND, Fitton TP, et al. Aortic valve replacement and concomitant mitral valve regurgitation in the elderly: impact on survival and functional outcome. Circulation 2005;112:I443-7.

10. Baran C, Durdu MS, Gumus F, et al. Sutureless aortic valve replacement with concomitant valvular surgery. J Thorac Cardiovasc Surg 2018;155:2414-22.

11. Deniz H, Sokullu O, Sanioglu S, et al. Risk factors for posterior ventricular rupture after mitral valve replacement: results of 2560 patients. Eur J Cardiothorac Surg 2008;34:780-4.

12. Vogt F, Moscarelli M, Nicoletti A, et al. Sutureless Aortic Valve and Pacemaker Rate: From Surgical Tricks to Clinical Outcomes. Ann Thorac Surg 2019;108:99-105.

13. Robich MP, Schiltz NK, Johnston DR, et al. Risk Factors and Outcomes of Patients Requiring a Permanent Pacemaker After Aortic Valve Replacement in the United States. J Card Surg 2016;31:476-85.

14. Concistrè G, Chiaramonti F, Bianchi G, et al. Aortic Valve Replacement With Perceval Bioprosthesis: SingleCenter Experience With 617 Implants. Ann Thorac Surg 2018;105:40-6.

15. Chalmers J, Pullan M, Mediratta N, et al. A need for speed? Bypass time and outcomes after isolated aortic valve replacement surgery. Interact Cardiovasc Thorac Surg 2014;19:21-6. 